\title{
The summertime "heat" low over Pakistan/northwestern India: evolution and origin
}

\author{
Massimo Bollasina · Sumant Nigam
}

Received: 17 February 2010/ Accepted: 5 July 2010/Published online: 15 July 2010

(C) Springer-Verlag 2010

\begin{abstract}
A deep low in sea-level pressure is present from May to September over Pakistan and northwestern India (hereafter, the Pak-India low). It is often referred as the "heat" low to convey the significance of surface thermal effects reckoned to be important for its origin. The present analysis, rooted in observations and diagnostic modeling, suggests that the Pak-India low is influenced both by regional and remote forcing. Regionally, the influence of Hindu Kush mountains is found to be stronger than the impact of land-surface heating and attendant sensible heating of the planetary boundary layer, questioning the suitability of the "heat" label in canonical references to this circulation feature. Observational analysis indicates that the notable May-to-June deepening of the Pak-India low and its further deepening in July, however, arises from remote forcing-the development of monsoon deep-convection over the Bay of Bengal and eastern India in June and July. It is hypothesized that the associated upstream descent over Iran-Turkmenistan-Afghanistan (i.e. east of the Caspian Sea) and related low-level northerlies over the Elburz-Zagros-Hindu Kush mountains contribute to the strengthening of the Pak-India low in June (and July) from interaction with regional orography.
\end{abstract}

Keywords Heat low · Desert heating . Orographic forcing · South Asian monsoon

M. Bollasina $\cdot$ S. Nigam $(\bowtie)$

Department of Atmospheric and Oceanic Science,

University of Maryland, 3419 Computer and Space Science

Building, College Park, MD 20742-2425, USA

e-mail: nigam@atmos.umd.edu

\section{Introduction}

"Heat lows" (also referred as "thermal lows") are characterized by low surface pressure (3-10 hPa lower than surrounding regions) and purportedly caused by intense heating of the land-surface (and overlying atmosphere) from solar radiation. Heat lows are found over the tropicalsubtropical continents in summer when insolation is at its maximum. In particular, deep heat lows, favored by clear skies, lack of vegetation, and small evaporation, are ubiquitous features over the deserts, and as such, are found in northern and southwestern Africa, southwestern North America, central Spain, northwestern and northeastern Australia, the Tibetan Plateau, Saudi Arabia, southern Pakistan, and the Thar desert of India (e.g. Warner 2004). Key features of the heat lows are summarized in a recent review (Johnson 2003). The dynamical aspects of the lows have been investigated using realistic (e.g. Portela and Castro 1996) and idealized numerical experiments (e.g. Rácz and Smith 1999; Spengler and Smith 2008).

The low over Pakistan and northwestern India (hereafter the Pak-India low; e.g. Ramage 1966; Chang 1972; Joshi and Desai 1985; Sikka 1997) stands out as the deepest low in the global tropics during spring and summer, and is a key element of the South Asian summer monsoon. It develops in April-May along with the low-level southwesterly wind regime over the Arabian Sea, a month before monsoon rains commence over western India (e.g. Ramage 1966). Monsoon depressions, the majority of which forms at the head of the Bay of Bengal move westward across the Indian Subcontinent, eventually merging and dissipating in the Pak-India low (e.g. Keshavamurty and Awade 1970). Springtime fluctuations of this low have been linked to subsequent variations of the All-India monsoon rainfall (e.g. Parthasarathy et al. 1992). Mean sea-level pressure 
over the low region in May is, in fact, an important parameter in the multivariate regression models of Indian summer monsoon rainfall (e.g. Singh et al. 1995). Despite the importance of the Pak-India low in the South Asian summer monsoon evolution and variability, its salient features remain to be fully characterized. Most descriptions offer a local, one-dimensional perspective, and often, in reference to the nearby Persian trough (Bitan and Sa' aroni 1992) and Saudi Arabian low (e.g. Ramage 1966; Blake et al. 1983). ${ }^{1}$ The spatiotemporal sparseness of in situ observations in desert regions undoubtedly hampers the characterization efforts.

The primary motivation for this study was the observation that the Pak-India low is deepest in July-not in May when the land-surface is warmer and the sensible heating stronger-questioning the prevailing view on its origin that is manifest in the commonly used "heat" label. The low is moreover, nestled in the vegetated Indus River plain — not desert terrain—and just eastward of the Hindu Kush mountains (Fig. 1), raising further the possibility of orographic influence, which, if pertinent, finds no reference in the "heat" label. The recent availability of the European Centre for Medium-Range Weather Forecasts (ECMWF) 40-year global reanalysis data (ERA-40; Uppala et al. 2005) provided additional incentive to examine the 3D structure and evolution of this low, using dynamically/ thermodynamically consistent fields rooted in both local and neighboring observations (in situ and remotely sensed).

Clarification of the mechanisms generating the Pak-India low warrants a large-scale perspective on the dynamical and thermodynamical conditions as subsidence can be forced from remote regions as well (e.g. Yanai et al. 1992; Rodwell and Hoskins 1996). Subsidence over northwestern India and the Thar desert in summer has been linked to the monsoon build-up over Bay of Bengal (Das 1962). The entire Middle East, in fact, is under the influence of large-scale descent during much of the year: the Hadley cell descent is not the only contributor given the intensification and northward movement of subsidence in summer. In a seminal study, Rodwell and Hoskins (1996) showed descending motions over the Eastern Mediterranean and Middle East to be linked with the South Asian summer monsoon (the monsoon-desert link). In their modeling analysis, the Zagros mountain chain was important for the localization and intensification of the descent, through generation of regional anticyclonic low-level flow and southward advection of cold air, both leading to descending motions from Sverdrup

\footnotetext{
${ }^{1}$ Blake et al. (1983) and Smith (1986) used intensive observations of the 1979 summer and the international Summer Monsoon Experiment to analyze the radiative and thermodynamical aspects of the heat low over the Rub'al Kahli Desert.
}
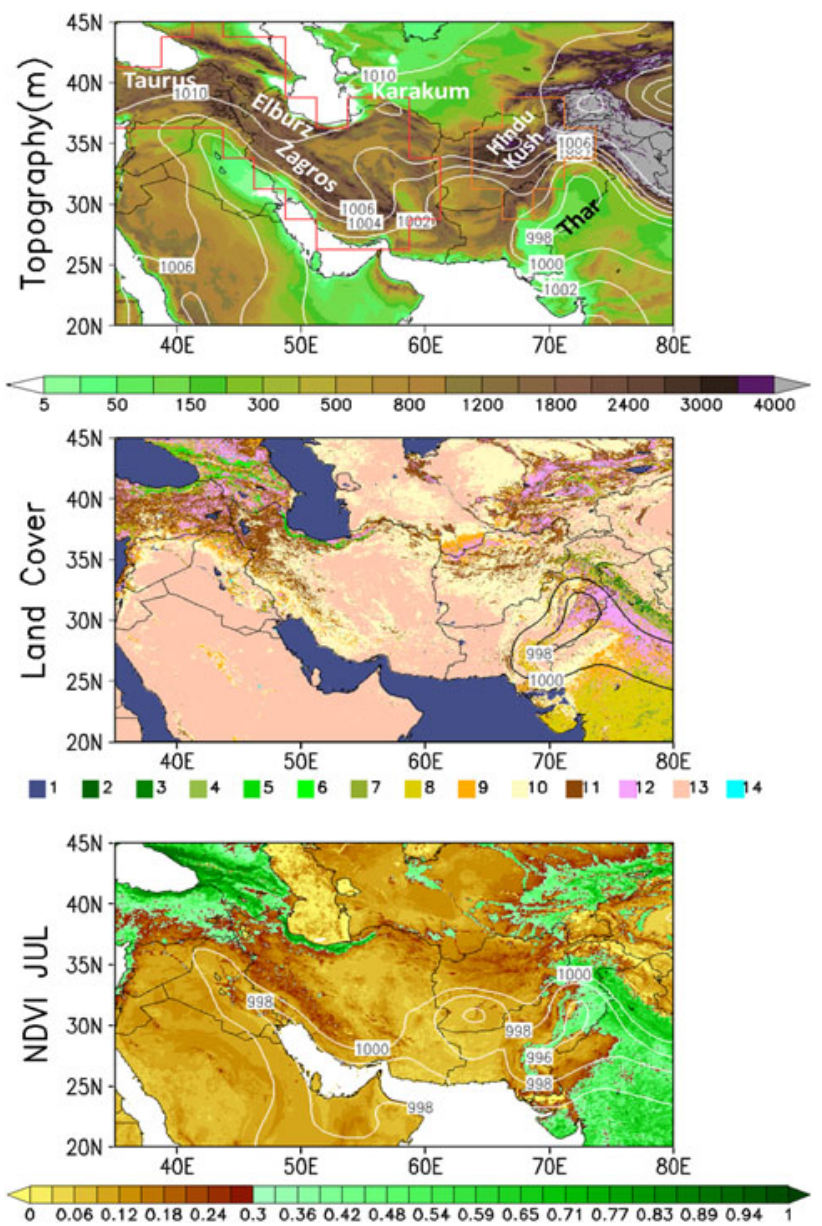

Fig. 1 From top to bottom: ETOPO1 1-min topography (m; colors) and May-July average sea-level pressure ( $\mathrm{hPa}$, white contours); UMD AVHRR 1-km land-cover classification and May-July average sealevel pressure ( $\mathrm{hPa}$; black contours, only values below 1,000 hPa are shown); July mean MODIS NDVI and July average sea-level pressure ( $\mathrm{hPa}$; white contours, only values below $1,000 \mathrm{hPa}$ are shown). Land cover classes are: 1 water, 2 evergreen needleleaf forest, 3 evergreen broadleaf forest, 4 deciduous needleleaf forest, 5 deciduous broadleaf forest, 6 mixed forest, 7 woodland, 8 wooded grassland, 9 closed shrubland, 10 open shrubland, 11 grassland, 12 cropland, 13 bare ground, 14 urban and built. The color lines in the top panel delineate the areas where orography (red Taurus, Zagros and Elburz; orange Hindu Kush) is removed in the model experiments. The red area actually extends to $28^{\circ} \mathrm{E}$ (the area is restricted in the picture to focus on regional details)

vorticity-balance and adiabatic thermodynamic considerations, respectively.

Is the Rodwell-Hoskins' monsoon-desert mechanism of relevance in the deepening of the Pak-India low in July? Although monsoon-induced subsidence to the immediate northwest is not collocated with this low, the related low-level circulation could contribute to the low's intensification through orographic interaction, a hypothesis investigated, observationally, in the present study. The role of regional orography in generating the Pak-India low from interaction with the zonal-mean flow is, however, 
investigated from numerical experiments with a steady linear primitive equation model. A significant role is indeed suggested in both nascent (May) and mature (July) phases of the low.

The paper is organized as follows: data and model are briefly described in Sect. 2. Section 3 describes the regional landscape and the seasonal, pentad, and diurnal variations of relevant dynamic and thermodynamic variables in the Pak-India low region, building a case for the role of non-thermal forcing (of the low) as well. Links with the large-scale atmospheric circulation, including its divergent component, strengthen the case. Diagnostic modeling of the low, in particular the orographic contribution is presented in Sect. 4. Discussion and concluding remarks follow in Sect. 5 .

\section{Datasets and the diagnostic model}

The main dataset used in this study consists of atmospheric and surface variables from the ERA-40 atmospheric reanalysis. Reanalysis data is available 6-hourly on a $320 \times 160$ gaussian grid (horizontal resolution of about $1.125^{\circ}$ ) and at 23 isobaric levels. The 1979-2001 period data was obtained from the National Center for Atmospheric Research archives. In the following analysis, data was averaged to produce daily and pentad climatologies, in addition to monthly ones.

Monthly surface air temperatures were obtained from the Climate Research Unit (CRU) TS 2.1 dataset (Mitchell and Jones 2005) at $0.5^{\circ}$ resolution. The study region's landsurface is described (Fig. 1) using the following data sets: land topography from the National Oceanic and Atmospheric Administration/National Geophysical Data Center (NOAA/NGDC) ETOPO1 1-arc minute global relief model (Amante and Eakins 1998); land cover from the University of Maryland/Department of Geography $1 \mathrm{~km}$ global classification dataset (http://glcf.umiacs.umd.edu/data/landcover/), based on 14 years (1981-1994) of imagery from the advance very-high resolution radiometer (AVHRR) which distinguishes 14 land cover classes; land vegetation development from version-5 of the TERRA/moderate resolution imaging spectroradiometer (MODIS) normalized difference vegetation index (NDVI) monthly data at $0.05^{\circ}$ horizontal resolution (MOD13C2.005) for the period 2000-2008 (https://lpdaac.usgs.gov/lpdaac/products/modis_products_ table/vegetation_indices/monthly_13_global_0_05deg_cmg/ v5/terra).

\subsection{Diagnostic model}

The steady linear primitive equation model is described in Nigam and Chan (2009) and in the references therein; only salient features are mentioned below. The model solves the eddy component (i.e. departure from the zonal average) of the linearized sigma- $p$ coordinate $\left(\sigma=p / p_{\mathrm{s}}\right.$, where $p$ and $p_{\mathrm{s}}$ are pressure and surface pressure, respectively) equations, given the zonally-symmetric basic state (temperature, zonal and meridional winds, and surface pressure). The ERA-40 orography, diagnosed 3D diabatic heating (Chan and Nigam 2009), sub-monthly transient heat and momentum fluxes, and the surface temperature constitute the model forcing. The basic state and model forcing are all computed from the 1979-2001 period ERA-40 reanalysis ( $2.5^{\circ}$ horizontal resolution, 23 isobaric levels). The diagnostic model is solved numerically, using the semi-spectral representation for the horizontal structure: 73 grid points between the two poles (i.e. $\Delta \theta=2.5^{\circ}$ ) and zonal Fourier truncation at wave number 60 . The vertical structure is discretized using 18 full-sigma levels. Momentum dissipation is exactly as in Nigam and Chan (2009) but the thermal dissipation is slightly modified to reflect the increased sensible heating in summer, through deeper thermal diffusion in the planetary boundary layer, larger drag coefficient in the related lower boundary condition, and from reduced Newtonian damping of temperature in the lower troposphere. ${ }^{2}$ Model output is transformed from sigma to pressure levels using linear interpolation in $\ln (\sigma)$, and sea-level pressure obtained from surface pressure using the hydrostatic equation and a fixed lapse rate. ${ }^{3}$

\section{Climatological features of the Pak-India low}

\subsection{The landscape}

The physical landscape and summertime land-cover/ vegetation in the Middle East and southwest Asia are shown in Fig. 1. Sea-level pressure is also shown using contours. The region is characterized by complex orography, with elevated mountain chains (e.g. peaks above 3,000 m): the Taurus in Turkey, the Zagros to the south and the Elburz to the north in Iran, and the Hindu Kush in Afghanistan and northwestern Pakistan. The land surface is prevalently arid or semi-arid (bare ground is peach, \#13, in Fig. 1 middle) with numerous deserts (e.g. Iranian, Karakumy, and Thar) and some cultivated areas (principally, the Indus River

\footnotetext{
The thermal diffusion coefficient is $30[1+\tan h\{10 \pi(\sigma-0.70)\}]$ instead of $30[1+\tan h\{10 \pi(\sigma-0.85)\}]$; the drag coefficient is $3.0 \times 10^{-3}$ as opposed to $1.0 \times 10^{-3}$ earlier; the Newtonian damping coefficient is now (25 days) $)^{-1}$ at all vertical levels.

${ }^{3}$ First, surface temperature is computed by interpolating the lowest sigma-level temperature to the surface using a $6.5 \mathrm{~K} \mathrm{Km}^{-1}$ lapse rate. Linear interpolation is then used to take $\ln \left(p_{\mathrm{S}}\right)$ to $\ln \left(p_{\mathrm{SL}}\right)$ (being $p_{S}$ surface pressure and $p_{S L}$ sea-level pressure) using the $p$-coordinate hydrostatic equation and the above-obtained surface temperature.
} 
plain). During July, vegetation is fully developed in the Indus River plain and western India (except over the Thar desert; see Fig. 1, bottom).

A wide area of low-pressure $(<1,002 \mathrm{hPa}$, for instance $)$ extends from Arabia to India during May-July, with the core of the Pak-India low defined by the lowest pressure closed contour (998 hPa). The low is located over the Indus River plain, with its western flank skirting the Hindu Kush mountain range (Fig. 1, top). The northern portion of the low is more dark pink than peach in Fig. 1 (middle), indicating a shrubland-cropland type land cover which is green during the period under consideration. Only the south-central sector is classified as bare ground. In particular, the core of the Pak-India low in July (when it is deepest, $\sim 996 \mathrm{hPa}$ ) is centered over a vegetated land surface (Fig. 1, bottom) - calling into question its wide reference as a "heat" low.

\subsection{Seasonal evolution}

The summertime evolution of the Pak-India low is shown in Fig. 2, along with surface air temperature (SAT). An expansive low, without a defined core, is present over Pakistan and northern India in May, with SAT exceeding $33^{\circ} \mathrm{C}$ over a wide swath of the Indian subcontinent and even $34^{\circ} \mathrm{C}$ over southern Pakistan. The low deepens substantially in June with the closed $996 \mathrm{hPa}$ contour defining its core, and is broadly coincident with the warmest SAT region $\left(>35^{\circ} \mathrm{C}\right)$. These distributions indicate the significance of surface thermal forcing in the deepening of the low, but not to an exclusive role. The low deepens a bit more in July, especially over southern Pakistan but, interestingly, without any further increase in SAT. The SAT, in fact, decreases in July by $1-2^{\circ} \mathrm{C}$ over the core of the low, and by several more degrees over western India and the northern Gangetic Plain, the latter due to the arrival of monsoon clouds and rain (see the following Fig. 3). The June-to-July evolution of sea-level pressure and SAT also suggests that the Pak-India low is maintained not only by surface thermal effects.

The thermal forcing of the low is investigated in Fig. 3, which shows the monthly ERA-40 sensible heat flux ${ }^{4}$ at $12 Z$ (5 p.m. in Pakistan and India). The flux should capture the peak heating of the atmosphere from the underlying land-surface. Sensible heating over the Pak-India low region is evidently large in May and June but focused over southeastern Pakistan and western India, i.e. south of the

\footnotetext{
4 The unassimilated reanalysis variables, such as sensible heat flux, are impacted by the biases of the assimilating model, including physical parameterizations. The ERA-40 sensible heat flux is, nonetheless, analyzed here as long-term observations of this quantity are non-existent, and because of our focus on the large-scale features, especially in context of monthly evolution, i.e. relative variations.
}

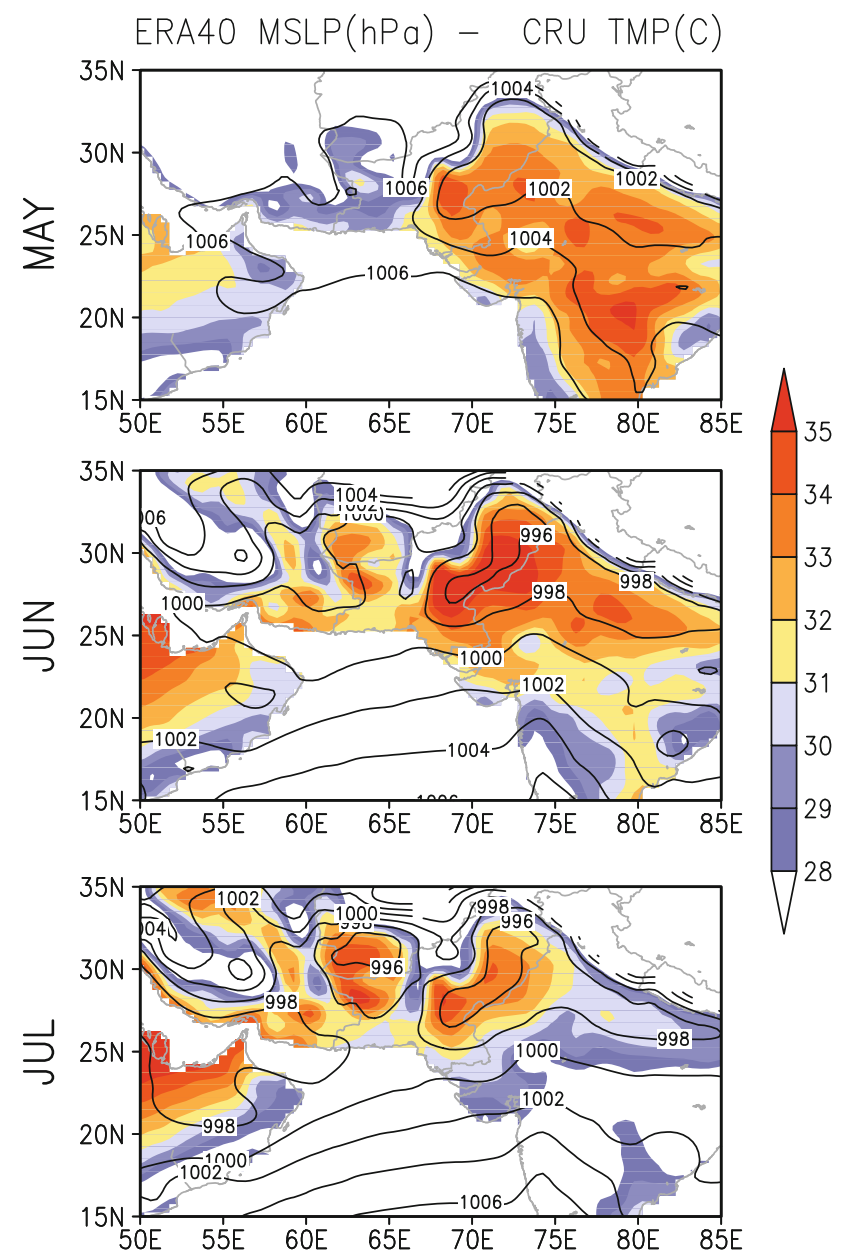

Fig. 2 ERA-40 sea-level pressure (hPa, contours) and CRU surface air temperature $\left({ }^{\circ} \mathrm{C}\right.$, shaded) for (top to bottom) May, June and July

core of the low (compare to Fig. 2). The northern lobe of the low, interestingly, is not a notable sensible heating zone (flux is 50\% smaller than to the south) as it receives more precipitation than the southern sector. The heating, like SAT, is moreover diminished in July when the low is the deepest, coincident with the substantial increase of precipitation over the region. ${ }^{5}$ The lack of co-location and different peak timings of sea-level pressure and surface thermal variables suggest that non-thermal processes may also be important in the evolution of the Pak-India low.

Potential temperature and vertical motion across the low are shown in a latitude-height cross-section in Fig. 4 (average between $70^{\circ} \mathrm{E}$ and $74^{\circ} \mathrm{E}$ ) for May (left) and July (right). The dip in potential temperature contours, as evident between $25^{\circ} \mathrm{N}$ and $30^{\circ} \mathrm{N}$ in May, denotes heating of the atmosphere, which extends up to $\sim 700 \mathrm{hPa}$. The pressure vertical velocity is negative (rising motion)

\footnotetext{
5 The extent to which increased precipitation in July contributes to the intensification of the low will be analyzed using WRF-based experiments in the future.
} 


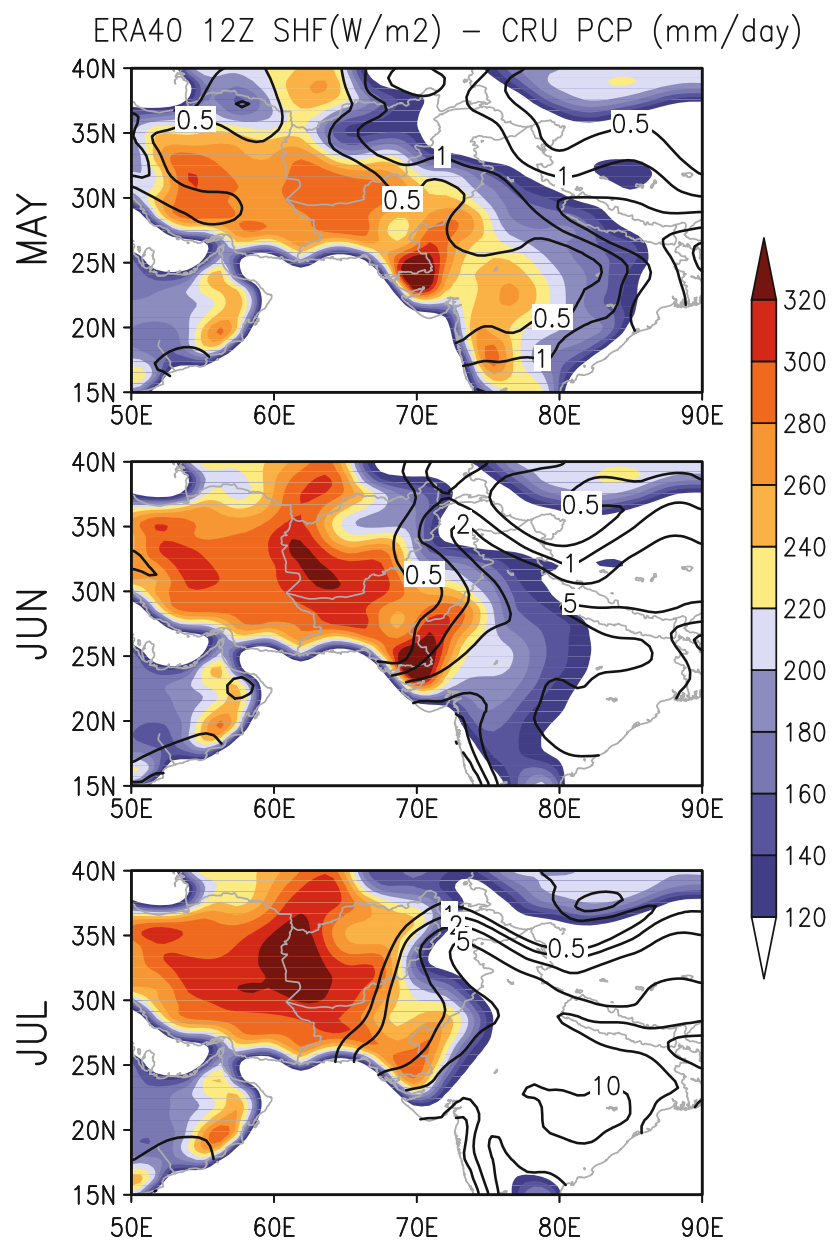

Fig. 3 Sensible heat flux at $12 \mathrm{Z}\left(\mathrm{W} \mathrm{m}^{-2}\right.$, shaded $)$ and $\mathrm{CRU}$ precipitation (mm day ${ }^{-1}$, contours) for (top to bottom) May, June and July

beneath this level and positive (sinking motion) above it, which must generate horizontal divergence near $700 \mathrm{hPa}$. The heating of the atmosphere is evidently not as deep in July (only up to $\sim 800 \mathrm{hPa}$ ) and the sinking motions in the mid-to-upper troposphere are, notably, absent in this month, both reflecting the advance of the monsoon (see also Fig. 3). Large upward velocity along the southern slopes of the Himalayas, associated with stable air, denotes strong orographic uplift.

\subsection{Pentad evolution}

The evolution of vertical motion and horizontal divergence above the core of the Pak-India low is examined at pentad resolution in Fig. 5 to shed light on the steep drop in sealevel pressure between May and June (Fig. 2). Upward motion develops near the surface in March-April, and intensifies and extends up to $775 \mathrm{hPa}$ by May. Subsidence builds up in the mid-to-upper troposphere, with a 2-3 pentad duration spike in the latter part of May. This spike is reflected in weaker upward motions near the surface (and the weakening of the low). The abatement of upper-level subsidence, interestingly, leads (by a few pentads) the intensification of near-surface upward motions (and the deepening of the low) in late June. Arrival of monsoon rains and related deep convection in the second half of July drastically alter vertical motions in the mid-toupper troposphere, from sinking to rising. The changes are more muted near the surface. The structure of horizontal divergence-an affirmation of the continuity equationreveals the presence of a shallow ( $<100 \mathrm{hPa}$ thick) convergent layer near the ground that is topped by a deep (several $100 \mathrm{hPa}$ thick) divergent layer. Sea-level pressure development (not displayed) shows the Pak-India low to be deepest at the end of June. The deepening, as noted above, is preceded by rapid reduction in upper-level subsidence, suggesting that the Pak-India low, while originating from surface heating, is influenced by larger-scale regional circulations, including regional orographic effects (e.g. Wu et al. 2009) and the monsoon (as shown later).

The presence of multiple influences is also indicated by analysis of the position of the core of the Pak-India low. Heat lows, owing their existence principally to surface thermal forcing, are essentially stationary features. Broadly, this is the case for the Pak-India low, as well. Tracking the core's position at pentad resolution using 23 years of ERA-40 reanalysis, however, shows the core, located over southeastern Pakistan in late April, to migrate northeastward while intensifying. ${ }^{6}$ The core's position, however, does not track the warmest SAT region.

\subsection{Diurnal cycle}

The diurnal variation of potential temperature and vertical motion over the northern and southern sector of the PakIndia low are examined in Fig. 6 in May and June when the low develops and deepens. Variations are analyzed separately in the sectors in view of differences in the underlying land-surfaces: the northern sector is classified as croplands while the southern one is more arid (cf. Fig. 1 middle and bottom). Nighttime and daytime conditions are represented by the $00 \mathrm{Z}$ and $12 \mathrm{Z}$ (5 a.m. and $5 \mathrm{p} . \mathrm{m}$. local time, respectively) profiles (blue and red, respectively). Only the daytime minus nighttime difference is shown in case of potential temperature.

\footnotetext{
6 The core location is identified by successive searches of the point where sea-level pressure is lower than its eight surrounding points. Examination of 23 maps for each pentad shows the core to be located in the following area $\left(68.625^{\circ} \mathrm{E}-70.875^{\circ} \mathrm{E}, 27^{\circ} \mathrm{N}-28.125^{\circ} \mathrm{N}\right.$; southeastern Pakistan) in 15 of the 23 cases during 11-15 April. About a month later (16-20 May), 17 of the 23 centers are found in the area $\left(72^{\circ} \mathrm{E}-74.25^{\circ} \mathrm{E}, 29.25^{\circ} \mathrm{N}-31.5^{\circ} \mathrm{N}\right.$; northeastern Pakistan).
} 
Fig. 4 Latitude-vertical crosssection of pressure-vertical velocity (hPa day ${ }^{-1}$, shaded), and potential temperature $\left({ }^{\circ} \mathrm{C}\right.$, green contours $)$ longitudinally averaged between $70^{\circ} \mathrm{E}$ and $74^{\circ} \mathrm{E}$ for May (left) and July (right). Vertical velocity in $z$-coordinates has opposite sign to the velocity displayed here

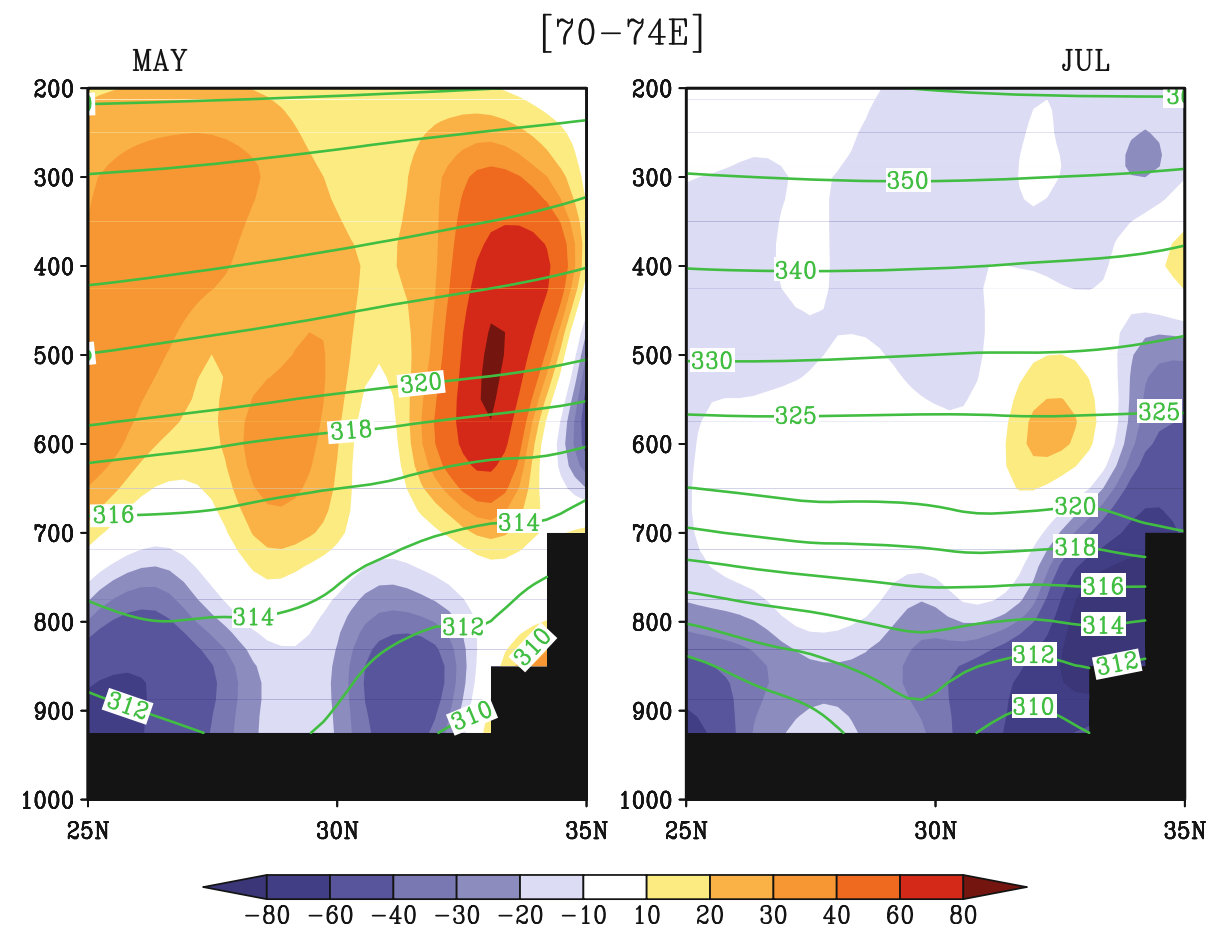

In the southern sector, diurnal variability is robust, penetrating into the mid-troposphere. Daytime ascending motions in the 1,000-800 $\mathrm{hPa}$ layer are replaced by strong subsidence at night; the ascent is more vigorous and deeper in June, when the land-surface is warmer (cf. Fig. 2). These variations are typical of those encountered in desert regions (e.g. Sikka 1997; Blake et al. 1983; Smith 1986). The large near-surface diurnal range in potential temperature, in June, especially, reflects the super-adiabatic lapse rate conditions in the afternoon and a stable near-surface layer (if not an inversion during May) during nighttime.

The northern sector of the low, however, exhibits very different vertical velocity profiles: both daytime and nighttime motions penetrate into the mid-troposphere, attaining maximum amplitudes much above the surface. More noteworthy is the occurrence of daytime (nighttime) descent (ascent), which is not typical even of the circulations developing over flat vegetated surfaces. The diurnal temperature range is also smaller than in the southern sector. Such diurnal variability, including deep ascent/descent, likely reflects the presence of regionalscale circulations, possibly influenced by orographic effects.

The structure of diurnal variability in the southern and northern sectors of the Pak-India low is thus quite different, with the former exhibiting desert-like structure. The distinction supports the notion that mechanisms other than surface thermal effects also contribute to the development of the Pak-India low. 

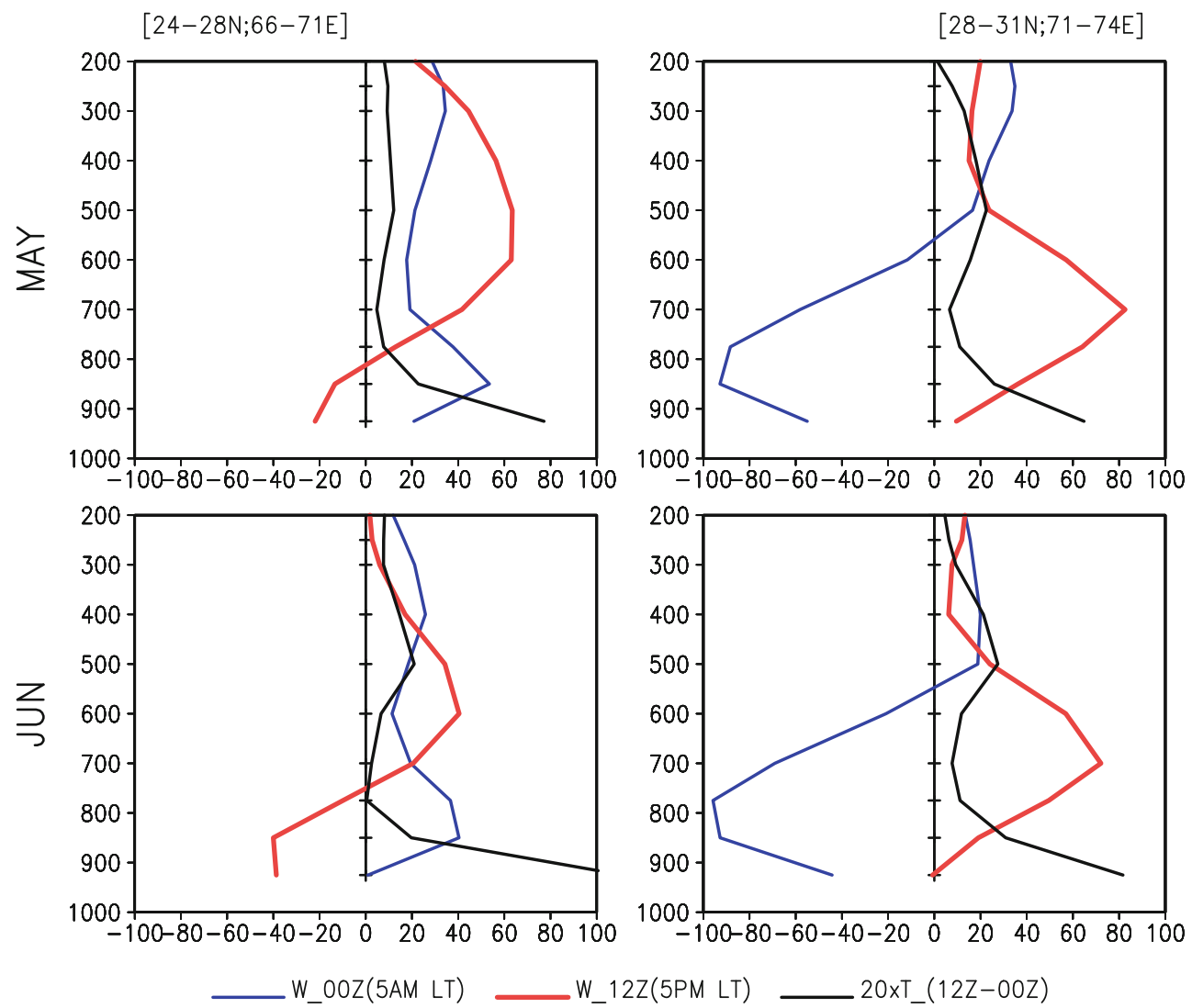

Fig. 6 Diurnal variation of the vertical profiles of pressure vertical velocity $\left(\mathrm{hPa}\right.$ day $\left.^{-1}\right)$ and daily range of potential temperature $\left({ }^{\circ} \mathrm{C}\right.$, black) averaged over (left) the southern sector of the low $\left(66^{\circ} \mathrm{E}-71^{\circ} \mathrm{E}, 24^{\circ} \mathrm{N}-28^{\circ} \mathrm{N}\right)$ and $(r i g h t)$ its northern sector $\left(71^{\circ} \mathrm{E}-74^{\circ} \mathrm{E}\right.$,

\subsection{The large-scale circulation context}

The evolution of the Pak-India low is examined in the context of the developing large-scale circulation in Fig. 7. Full fields are shown in April and the monthly increments thereafter. ${ }^{7}$ Sea-level pressure is lowest $(\sim 1,006 \mathrm{hPa})$ along the Pakistan-India border (and in the eastern Gangetic Plain) even in April. The low-level westerlies confined to the south of the Zagros mountain range become diffluent upon entering the Indian subcontinent, with the northern stream skirting the nascent Pak-India low. Sea-evel pressure drops precipitously in the subtropics in subsequent months, with the Pak-India low region as one of the foci; a 5-6 hPa decline occurs each month. ${ }^{8}$

\footnotetext{
7 The sea-level pressure change is preferred to the full field in complex orography regions as the former underemphasizes the biases introduced by the below-ground interpolation/extrapolation schemes in computation of sea-level pressure.

${ }^{8}$ The pattern of the low-level horizontal circulation in the region of the low (i.e. westerly flow; see the following Fig. 8) suggests that thermal advection from the heating area may contribute to downstream warming (and related low sea-level pressure development) over the Gangetic Plain (cf. Fig. 2).
}

$28^{\circ} \mathrm{N}-31^{\circ} \mathrm{N}$ ). For vertical velocity, the $00 \mathrm{Z}$ and $12 \mathrm{Z}$ profiles are displayed (blue and red, respectively). The temperature range is defined by the difference $12 \mathrm{Z}$ minus $00 \mathrm{Z}$, and it has been multiplied by 20 in order to fit to the same scale. Local time is UTC +5

Following Rodwell and Hoskins' (1996) monsoon-desert hypothesis linking the aridity of remote northwestern regions to monsoon convection over South Asia, the impact of eastern Indian Ocean and the Bay of Bengal convection (key monsoon convection zones) on the Pak-India low region is assessed from the structure of upper-level divergent circulations (Fig. 8). The 200-hPa divergent outflow is notably strong over Southeast Asia in May with divergent winds directed toward a broad area from western India to eastern Iran, and primary convergence over western Pakistan and southern Afghanistan. This upper-level convergence switches to divergence at lower levels, with a node at $400-500 \mathrm{hPa}$ (not shown). The 700-hPa divergence (also not shown) is a mirror image of the upper-level pattern at large scales, modulated by surface effects, including orography. Deep convection and related upper-level outflow intensifies and moves northward to the Bay of Bengal in July in conjunction with monsoon onset over eastern India. Upperlevel divergent flow to the northwest is now principally focused over the eastern Mediterranean (Rodwell and Hoskins 1996), but with a secondary convergence center over Iran-Turkmenistan-Afghanistan (i.e. east of the Caspian Sea). Can the low-level divergent flow induced by upper-level 


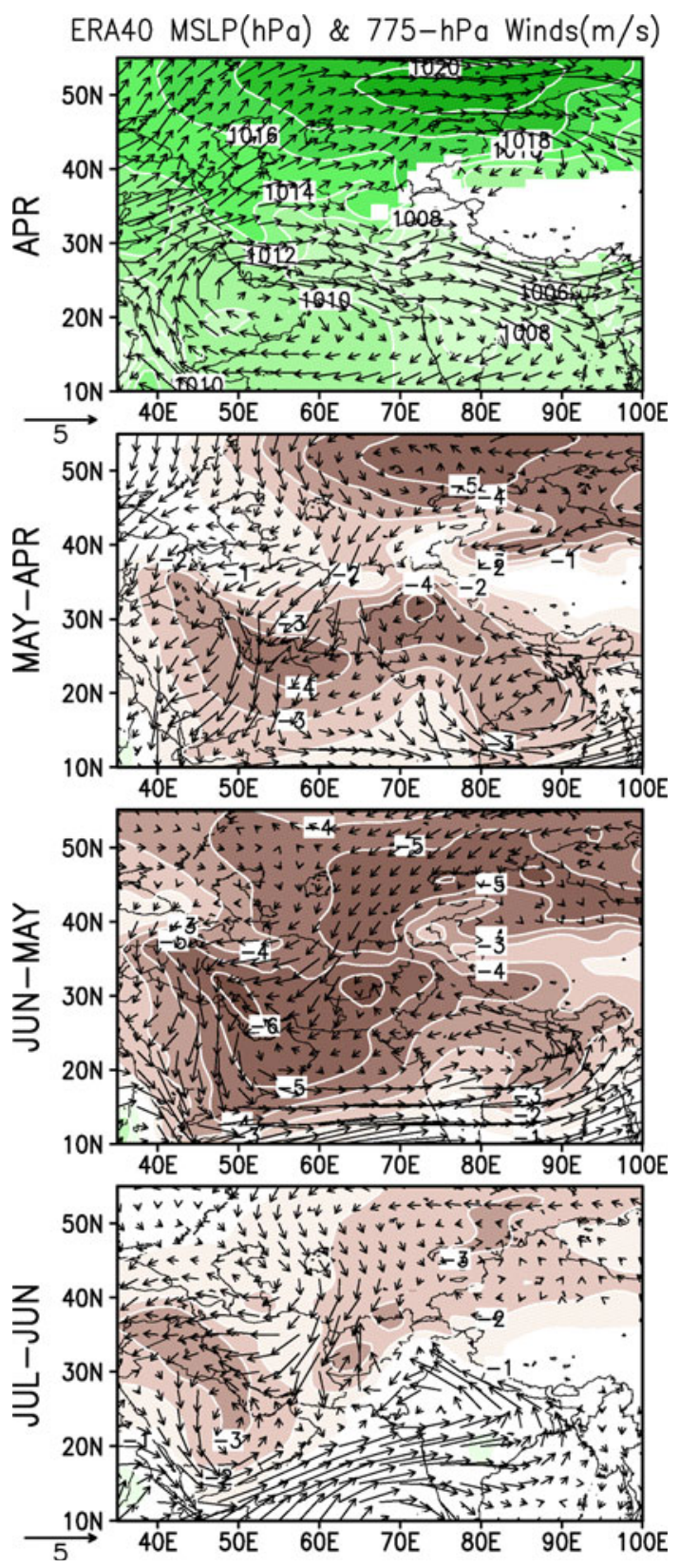

Fig. 7 Sea-level pressure (hPa, shaded), and 775-hPa winds $\left(\mathrm{m} \mathrm{s}^{-1}\right)$ for April (top), and differences (top to bottom) May-April, June-May, July-June

convergence (and subsidence) in these regions (but ultimately by monsoon deep-convection much farther to the east) be consequential for local sea-level pressure and circulation development (e.g. the Pak-India low evolution)? The monsoon-desert hypothesis of Rodwell and Hoskins (1996) encourages pursuit of the idea that the Pak-India low may be forced, in part, by the low-level divergent (and rotational) flow. This forcing would manifest not directly, but from its interaction with regional orography.

The idea is difficult to pursue, observationally, given the challenge of attributing divergent flow to various processes, especially in complex terrain regions. The 775-hPa streamlines are nonetheless superposed on regional orography in Fig. 8 to broadly note the salient features: a weak anticyclonic center is present over the Karakum desert in May; in July it intensifies into a prominent ridge positioned northwestward over the Caspian Sea (with strong northerly flow over western Afghanistan), broadly tracking the movement of the upperlevel convergence (low-level divergence) zone. ${ }^{9}$ The ridge will, of course, not be collocated with the divergence zone. Even if this remotely induced divergence were its principal forcing - unclear given the complex regional orography- the ridge placement will be determined by the nature of the vorticity balance: the large-scale (Sverdrup) balance would, for example, result in the ridge being to the west. Regardless of how this ridge is forced, it generates northerly flow over the mountains: over the western Hindu Kush in May, and more extensively, over the eastern Zagros, Elburz, and Hindu Kush ranges in July. The mountain ranges, in particular the Hindu Kush, deflect the flow, and while it is crossing the southern slopes, if potential vorticity $[\equiv(f+\zeta) / \mathrm{H}$; with $f$ the Coriolis parameter, $\zeta$ the relative vorticity, and $H$ the fluid column height] is conserved, $\zeta$ will become more cyclonic (i.e. positive) for $f$ decreasing and $H$ increasing, not inconsistent with the observed flow structure. Such mechanisms are best investigated by a modeling analysis where the divergent flow can be attributed to various processes.

\section{Role of orography and land-surface in development of the Pak-India low: a diagnostic modeling analysis}

The steady, linear primitive-equation model used here cannot capture the interaction of the remotely-induced divergent (and rotational) flow with regional orographyof the kind posited above for deepening of the Pak-India low from intensifying Bay of Bengal convection in June and July. It can, however, provide an estimate of the role of regional orographic features in the generation of the low. ${ }^{10}$

\footnotetext{
${ }^{9}$ Liu et al. (2007) have argued that the anticyclone is generated by the blocking and deflection of westerly flow by the Himalayan-Tibetan orography. The blocking and splitting of the westerly flow is welldocumented in winter and spring (e.g. Murakami 1987), but not for the peak summer monsoon season. However, as the westerly flow in July is present at higher latitudes, the upstream ridge observed in this period likely originates from the monsoon-induced descent over this region.

${ }^{10}$ Estimating this role is challenging, especially from diagnostic modeling where diabatic heating modifications in response to altered orography are not computed, and thus not considered. Fortunately, orography is being modified in a very arid region here, limiting heating changes and their impact. Regardless, linear diagnostic evaluations must be considered preliminary, as in this case. WRFbased modeling - underway-should yield a more definitive assessment of both dynamical and thermodynamical effects engendered by changes in regional orography, assuming that the model simulation with full forcing is realistic.
} 

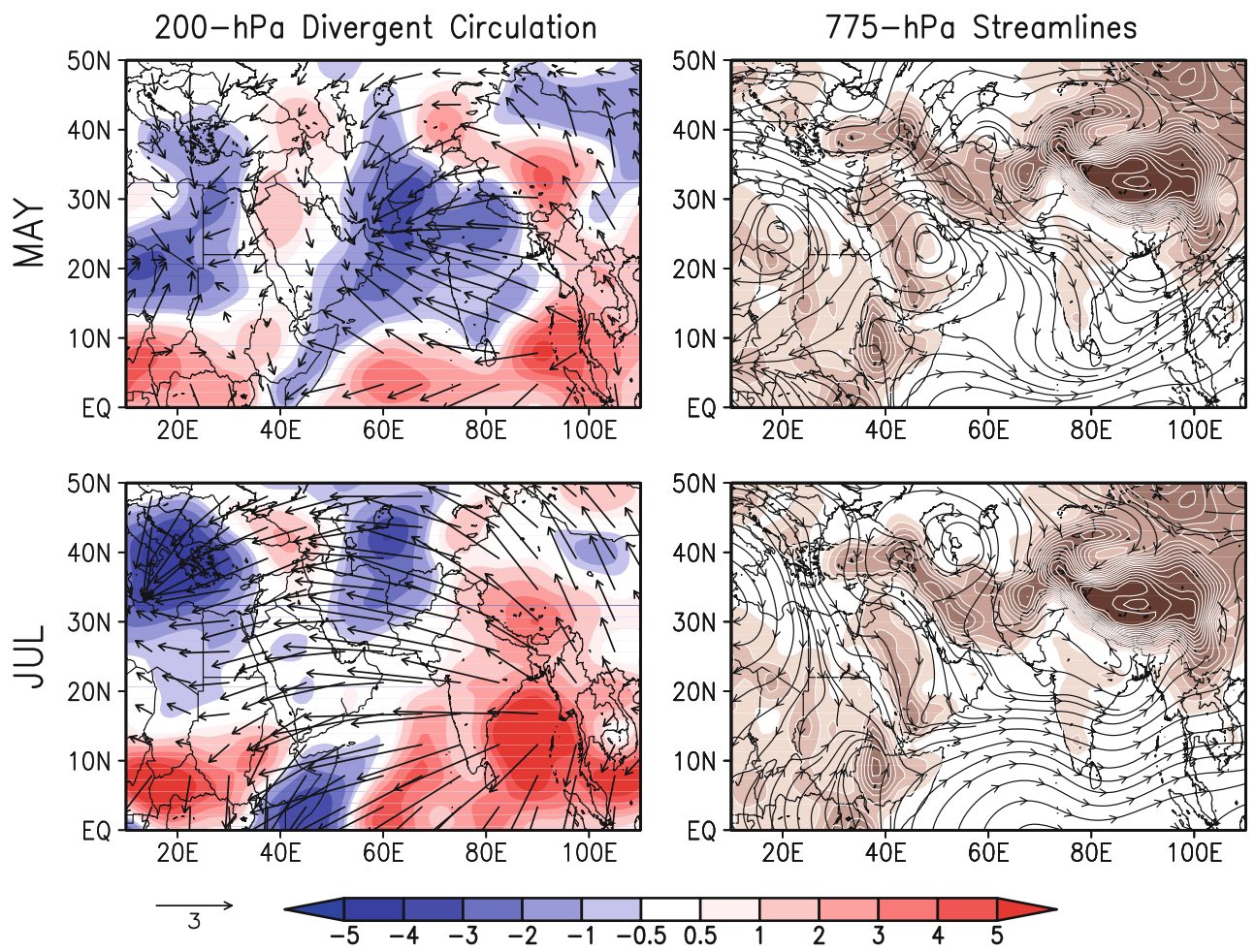

Fig. 8 Left Divergent wind ( $\mathrm{m} \mathrm{s}^{-1}$, arrows) and its divergence $\left(\times 10^{-6} \mathrm{~s}^{-1}\right.$, shaded) at $200 \mathrm{hPa}$ for May (top) and July (bottom). Right 775-hPa streamlines on ERA-40 orography ( $\mathrm{m}$, brown shades with white contours every $300 \mathrm{~m}$ ) for May (top) and July (bottom)

Three model solutions are discussed, including the control case (CTL) which is a simulation of summer stationary waves using all forcing (cf. section 2). The realism of this simulation will be an indicator of the suitability of this model. The other two solutions are the "no-mountain" simulations, both generated with forcing as in CTL but after removal of regional orographic features (as marked in Fig. 1, top): the Taurus-Elburz-Zagros mountains extending across Turkey and Iran are removed in the first simulation (referred as 'No-Zagros Taurus') while the Hindu Kush range in Afghanistan and Pakistan is zeroed out in the second one (the 'No-Hindu Kush'). The impact of surface thermal forcing in the Pak-India low region is also simulated in another sensitivity experiment.

\subsection{Control simulation}

The May and July sea level pressure in the CTL simulation (Fig. 9, top panels) should be compared with their observed counterparts (Fig. 2). The Pak-India low is evident in May along with its deepening in July, with core values generally consistent with ERA-40. The model, however, tends to extend the low-pressure region too far westward (toward Iran), perhaps because it cannot represent the non-linear aspects of the flow's interaction with orography. The model's performance is further assessed by examining the
850-hPa streamfunction and $600-\mathrm{hPa}$ vertical velocity (Fig. 10). As with sea-level pressure, the streamfunction trough is placed more westward (over the Iran-Pakistan border) in May, and more eastward (over the western Himalayas) in July. The mid-tropospheric vertical velocity is simulated more closely in the region except for the stronger and somewhat shifted subsidence in the western Himalayan sector. This shift is related to the eastward placement of the monsoon trough (and related upper-level Tibetan anticyclone) in the simulation.

\subsection{Impact of regional orographic features}

The Taurus-Elburz-Zagros Mountains lead to lower sealevel pressure over the Middle East in both May and July (Fig. 9, middle panels, obtained as CTL minus 'No-Zagros Taurus' simulation): a $6-8 \mathrm{hPa}$ pressure drop centered over Iran in this linear diagnosis. The effect is evident at upper levels as well, as seen in the 850 streamfunction (Fig. 10) which also shows a modest feature over the Pak-India low region. The mountains thus generate a cyclonic near-surface circulation with descent over the southern slopes of the Zagros Mountain and the Persian Gulf. Note, vertical motions arise from kinematic interaction with orography, and to offset thermal advection by orographically forced circulation and/or diabatic 
$\operatorname{MSLP}(\mathrm{hPa})$
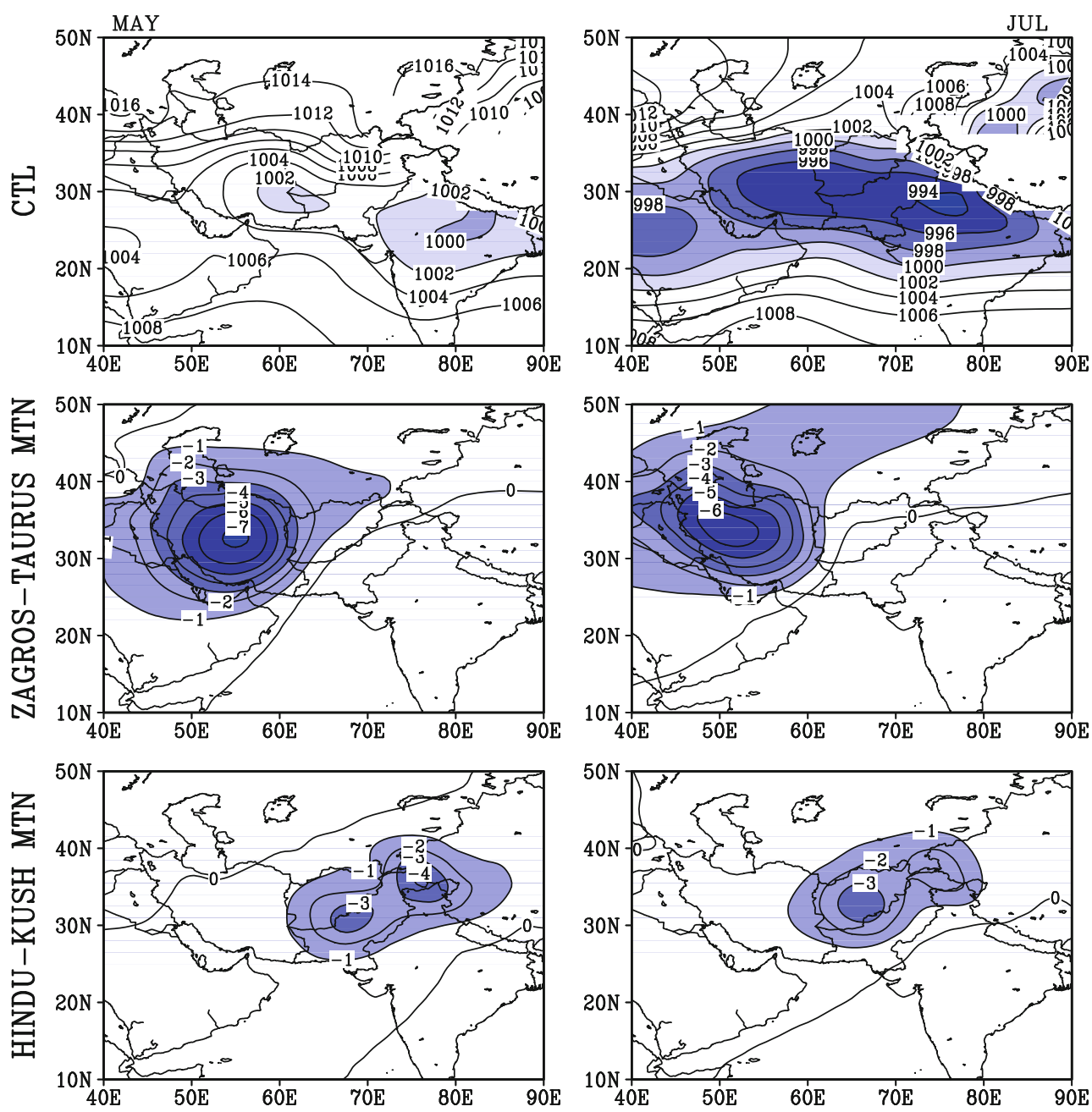

Fig. 9 May (left) and July (right) sea-level pressure (hPa) from the linear primitive equation model control run (CTL, top; values below $1,000 \mathrm{hPa}$ are shaded) and (middle and bottom) differences between CTL and the two no-mountain sensitivity runs (No Zagros-Taurus

and No Hindu Kush, respectively; differences greater than $1 \mathrm{hPa}$ are shaded). The effect of the mountains (Zagros-Taurus and Hindu Kush, respectively) is therefore represented

heating. The presence of descent (ascent) in northerly (southerly) regions in Fig. 10 (third panels from the top) reflects some contribution from the offsetting of cold (warm) advection under adiabatic conditions, applicable to the regional mountain experiments.

The Hindu Kush mountains of Afghanistan and Pakistan also generate low sea-level pressure (Fig. 9, bottom panels). While their contribution is comparatively modest $(\sim 3 \mathrm{hPa})$, it is in the core region of the Pak-India low, attesting to the relevance of non-thermal forcing mechanisms as well. The Hindu Kush impact on sea-level pressure is focused in northern Pakistan in May and over Afghanistan in July. In both months, these mountains generate descent over southern Pakistan and eastern Afghanistan, leading to severe aridity and lack of

vegetation in these regions (cf. Fig. 1), which must feedback on the low's intensity.

\subsection{Influence of the warm land-surface}

As noted earlier, the Pak-India low is often refereed as the "heat" low, reflecting the view that its origin is rooted in the heating of the underlying land-surface and attendant sensible heating of the planetary boundary layer (together, surface thermal forcing), a view contested in this paper. The influence of surface thermal forcing in the Pak-India low region is computed from the difference of two model solutions: the control simulation and another in which surface air temperature in the Pak-India low region $\left(62.5^{\circ} \mathrm{E}-75^{\circ} \mathrm{E}, 22.5^{\circ} \mathrm{N}-32.5^{\circ} \mathrm{N}\right)$ is capped at $30^{\circ} \mathrm{C}$ and 


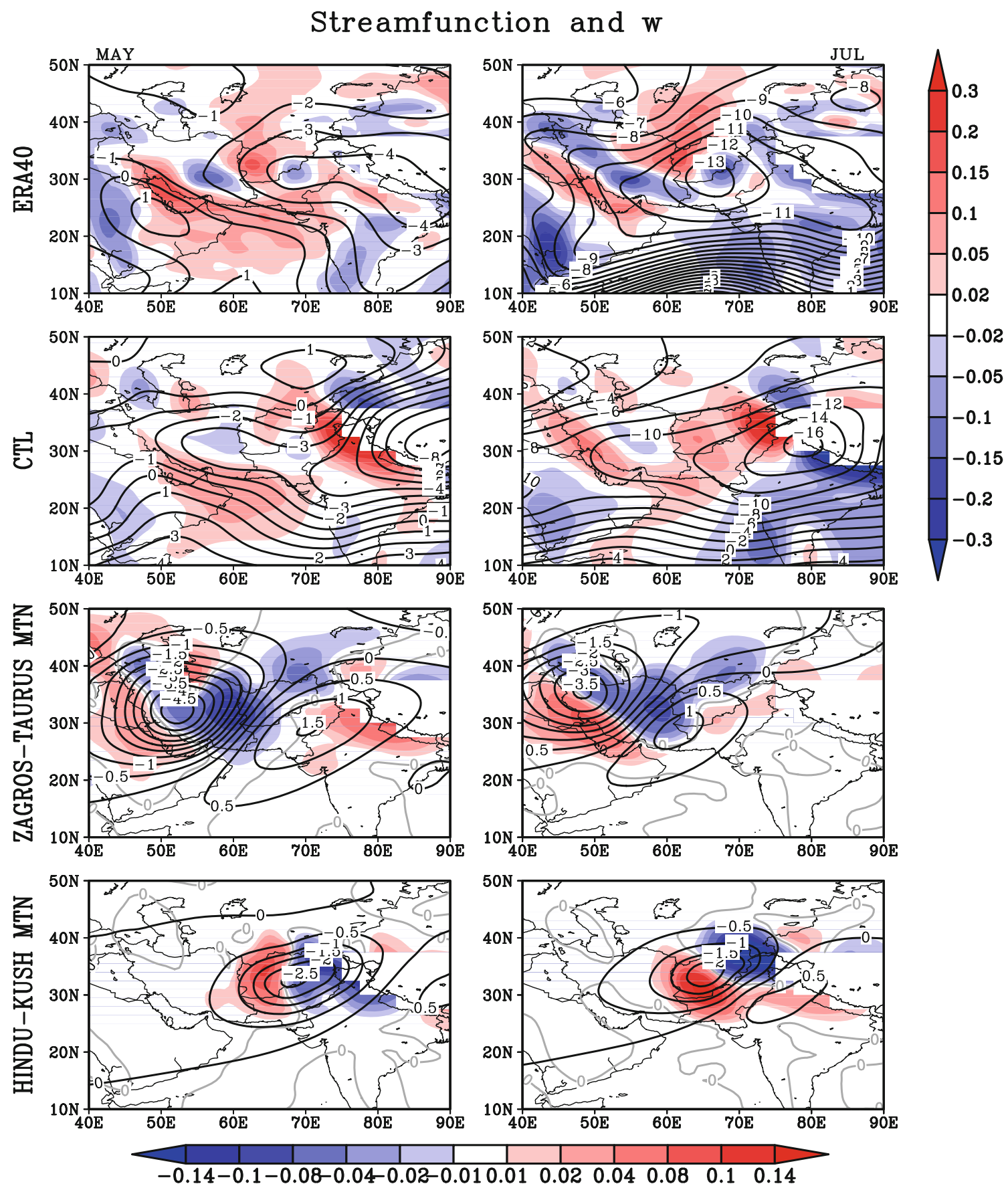

Fig. 10 May (left) and July (right) 850-hPa streamfunction $\left(\times 10^{-6} \mathrm{~m}^{2} \mathrm{~s}^{-1}\right.$, contours) and $600-\mathrm{hPa}$ vertical velocity $\left(\mathrm{Pa} \mathrm{s}^{-1}\right.$, shaded with the zero-contour line in grey) for (top to bottom) ERA40, CTL, and differences between CTL and the two no-mountain

diabatic heating (and transients) switched off in the planetary boundary layer $(\sigma \geq 0.85) .{ }^{11}$ The surface temperature

\footnotetext{
11 Ideally, the planetary boundary layer heating should be set to the surrounding region value, just as with surface air temperature. It was removed all together, however, to provide an upper estimate of the surface thermal impact.
}

sensitivity runs (No Zagros-Taurus and No Hindu Kush, respectively). The stream function is displayed as deviation from the global average, which corrects for model global biases

forcing in May and July (Fig. 11, top panels) fully covers the area of interest and is $\sim 5 \mathrm{~K}$ in the core region of the low. The response to surface thermal forcing (Fig. 11, bottom panels), consisting of a $1-2 \mathrm{hPa}$ signal over southwestern Pakistan, shows it to be consequential but only modestly compared to the Hindu Kush mountains, which generate a stronger signal (up to $3-4 \mathrm{hPa}$ ) over this 

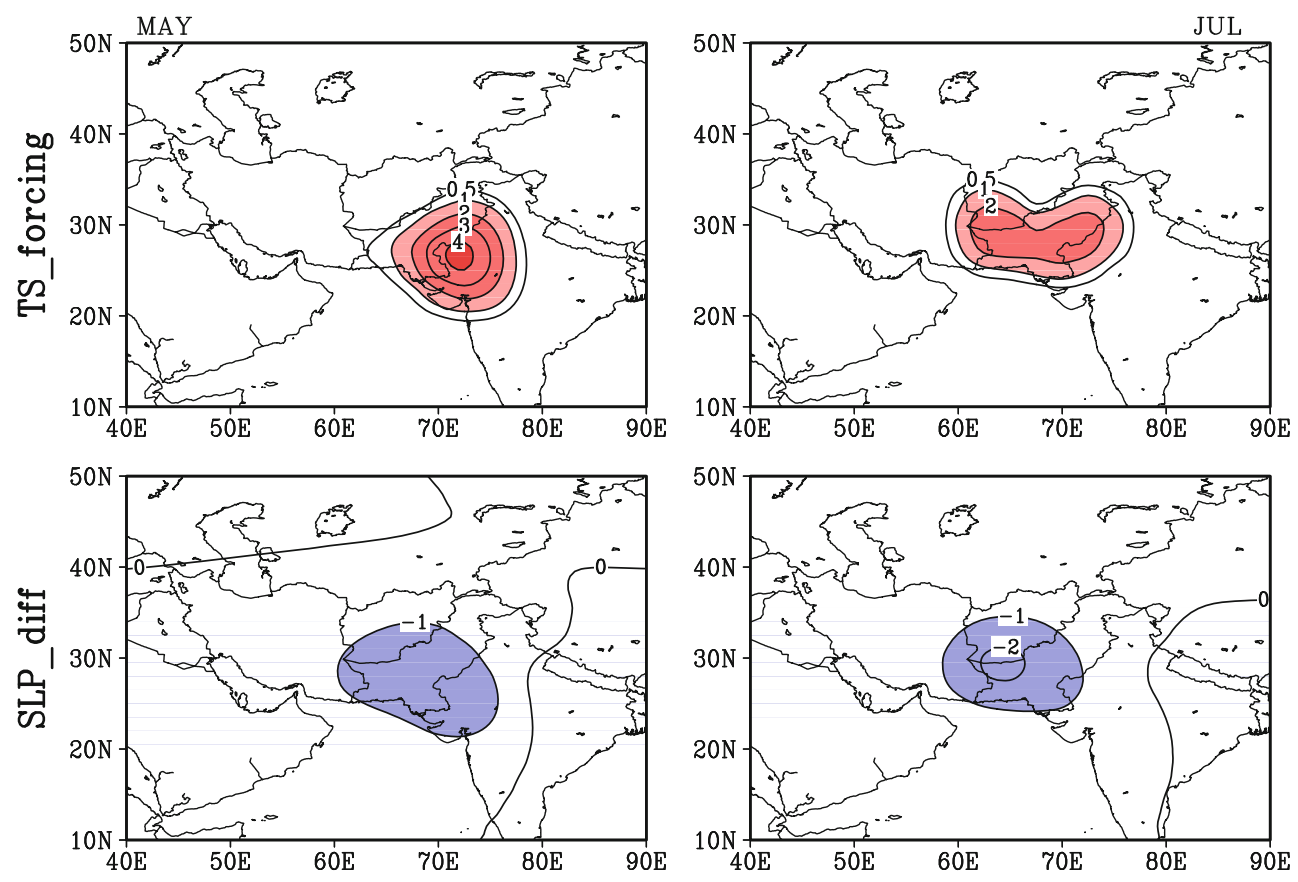

Fig. 11 May (left) and July (right) surface temperature forcing $\left({ }^{\circ} \mathrm{C}\right.$, top $)$, a component of surface thermal forcing. The latter's response, from the difference of CTL and surface-forcing runs, is shown in the bottom panels $(\mathrm{hPa})$. In the surface-forcing run, the

region and Afghanistan and northern Pakistan (Fig. 9 bottom panels). The orographic signal is, comparatively, even stronger further to the west where the Taurus-ElburzZagros mountains generate a sea-level pressure response of 6-8 $\mathrm{hPa}$. The surface thermal effects are expected to be of the same order as before.

\section{Discussion and concluding remarks}

The study was instigated by the hypothesis that the arid land-surface of southwest Asia plays a role in the development of the South Asian summer monsoon through generation of lower sea-level pressure from surface thermal effects. One can envision the resulting pressure distribution to generate southerlies in the Tropics, and southwesterlies beyond when the Coriolis force becomes significant: the southwesterly monsoon flow over the Arabian Sea and peninsular India. Subsequent interaction with regional orography-Western Ghats along the coast, regional plateaus in the interior and, of course, the Himalayan-Tibetan complex to the north-would influence the rainfall distribution. The hypothesis is conceptually appealing as it complements the monsoon-desert hypothesis of Rodwell and Hoskins (1996). If tenable, it would impart an element of symmetry to the monsoon-desert linkage. Interest in this hypothesis led us to investigate the Pakistan-India (Pak-India, for brevity) "heat" low, especially its prescribed surface temperature is capped at $30^{\circ} \mathrm{C}$ and diabatic heating and transient fluxes are removed in the planetary boundary layer over the Pak-India low region $\left(62.5^{\circ} \mathrm{E}-75^{\circ} \mathrm{E}, 22.5^{\circ} \mathrm{N}-32.5^{\circ} \mathrm{N}\right)$

evolution during the summer monsoon season which could be insightful on its origin.

Although drawn to this near-surface circulation feature because of its "heat" label which conveys the prevailing view on its origin-from surface thermal effects-we soon noted several observational aspects that encouraged questioning the suitability of this descriptive label. In particular:

- The Pak-India low is deepest in July, not in May when the land-surface is warmer and sensible heating stronger;

- The low is nestled in the vegetated Indus River plain, not over desert terrain;

- The low is positioned just eastward of the Hindu Kush mountains, raising the possibility of orographic influence;

- Sensible heating in early summer is focused over southeastern Pakistan/western India, i.e. south of the core of the low. Its northern sector, interestingly, is not a notable heating zone;

- Tracking the steepest monthly deepening of the low (May-to-June) at pentad resolution showed the deepening to be preceded by rapid reduction in upper-level subsidence, indicating the influence of larger-scale regional circulations;

- Diurnal variability in the northern and southern sectors of the Pak-India low is quite different, with only the latter exhibiting desert-like, day-to-night time differences; 
- The upper-level divergent flow to the northwest of deep monsoon convection over Bay of Bengal/eastern India is focused over eastern Mediterranean and also IranTurkmenistan-Afghanistan (Rodwell and Hoskins 1996). The remotely forced descent over the latter region (and related rotational response) is not factored in current explanations of the Pak-India low, especially its summer evolution.

Our analysis, rooted in observations (principally ERA-40 reanalysis) and diagnostic modeling, suggests that the Pak-India low is forced both by regional and remote forcing. Regionally, the influence of Hindu Kush mountains is found to be stronger than the impact of land-surface heating and attendant sensible heating of the planetary boundary layer (referred, together, as surface thermal forcing) by a factor of 1.5-2.0, questioning the suitability of the "heat" label in canonical references to this circulation feature.

Our observational analysis indicates that the notable May-to-June deepening of the Pak-India low and its further deepening in July, however, arises from remote forcingdevelopment of monsoon deep-convection over the Bay of Bengal and eastern India in June and July. The importance of monsoon convection for the upstream (northwest) region aridity was noted in the seminal analysis of Rodwell and Hoskins (1996). Here, we hypothesize that the upstream descent over Iran-Turkmenistan-Afghanistan (i.e. east of the Caspian Sea; noted in Rodwell and Hoskins' paper as well) and related low-level northerlies over the ElburzZagros-Hindu Kush mountains also contribute to the strengthening of the Pak-India low in June (and July) - not directly, but from interaction with regional orography. Modeling experiments with the weather research and forecasting (WRF) model are underway to test this hypothesis.

In summary, we find surface thermal forcing to have a limited role in the development of the Pak-India low; the forcing is somewhat influential in the low's southeastern sector (which has desert-like characteristics), principally, in its nascent phase. The study argues for a reconsideration of the physical processes important for the development of the Pak-India low. Advancing understanding of the development mechanisms of this summertime circulation feature is essential given its strong precursor links to the summer monsoon rainfall, a link captured in statistical prediction models, as noted in the Introduction.

Acknowledgments The MODIS data were provided by the NASA's Land Processes Distributed Active Archive Center (LP DAAC). The ERA-40 T106 data were provided by Dr D. Stepaniak at the NCAR's Computational and Information Systems Laboratory/Research Data Archive (CISL/RDA). The authors acknowledge support of NSF and DOE grants, ATM-0649666 and DEFG0208ER64548, respectively.
Massimo Bollasina was also supported by the Ann G. Wylie Dissertation Fellowship from the University of Maryland Graduate School, and by the Green Fund Foundation Award. This work constitutes part of the doctoral thesis of the first Author. The authors thank Dr. Thomas Spengler and an anonymous reviewer for their constructive remarks.

\section{References}

Amante C, Eakins BW (1998) ETOPO1 1 arc-minute global relief model: procedures, data sources and analysis. National Geophysical Data Center, NESDIS, NOAA, US Department of Commerce, Boulder, CO

Bitan A, Sa' aroni H (1992) The horizontal and vertical extension of the Persian Gulf pressure trough. Int J Climatol 12:733-747

Blake DW, Krishnamurti TN, Low-Nam SV, Fein JS (1983) Heat low over the Saudi Arabian desert during May 1979 (Summer MONEX). Mon Weather Rev 111:1759-1775

Chan SC, Nigam S (2009) Residual diagnosis of diabatic heat from ERA-40 and NCEP reanalyses: intercomparison with TRMM. J Clim 22:414-428

Chang J-H (1972) Atmospheric circulation systems and climates. Oriental Publish Co., Hawaii, p 328

Das PK (1962) Mean vertical motion and non-adiabatic heat sources over India during the monsoon. Tellus 14:212-220

Johnson RH (2003) Thermal low. In: Holton J, Pyle J, Curry JA (eds) Encyclopedia of atmospheric science, Academic Press, London, United Kingdom, pp 2269-2273

Joshi PC, Desai PS (1985) The satellite-determined thermal structure of heat low during Indian south-west monsoon season. Adv Space Res 5:57-60

Keshavamurty RN, Awade ST (1970) On the maintenance of the mean monsoon trough over North India. Mon Weather Rev 98:315-320

Liu Y, Hoskins B, Blackburn M (2007) Impact of Tibetan orography and heating on the summer flow over Asia. J Meteor Soc Japan 85B: $1-19$

Mitchell TD, Jones PD (2005) An improved method of constructing a database of monthly climate observations and associated highresolution grids. Int J Climatol 25:693-712

Murakami T (1987) Orography and monsoons. In: Fein JS, Stephens PL (eds) Monsoons, Wiley, New York, pp 331-364

Nigam S, Chan SC (2009) On the summertime strengthening of the Northern Hemisphere Pacific sea level pressure anticyclone. J Clim 22:1174-1192

Parthasarathy B, Rupa Kumar K, Munot AA (1992) Surface pressure and summer monsoon rainfall over India. Adv Atmos Sci 9:359-366

Portela A, Castro M (1996) Summer thermal lows in the Iberian peninsula: a three-dimensional simulation. Q J R Meteorol Soc 122:1-22

Rácz Z, Smith RK (1999) The dynamics of heat lows. Q J R Meteorol Soc 125:225-252

Ramage CS (1966) The summer atmospheric circulation over the Arabian Sea. J Atmos Sci 23:144-150

Rodwell MJ, Hoskins BJ (1996) Monsoons and the dynamics of deserts. Q J R Meteorol Soc 122:1385-1404

Sikka DR (1997) Desert climate and its dynamics. Curr Sci 72:35-46

Singh D, Bhadram CVV, Mandal GS (1995) New regression model for Indian summer monsoon rainfall. Meteorol Atmos Phys 55:77-86

Smith EA (1986) The structure of the Arabian heat low. Part II: bulk tropospheric heat budget and implications. Mon Weather Rev 114:1084-1102 
Spengler T, Smith RK (2008) The dynamics of heat lows over flat terrain. Q J R Meteorol Soc 134:2157-2172

Uppala SM et al (2005) The ERA40 reanalysis. Q J R Meteorol Soc 131:2961-3012

Warner TT (2004) Desert meteorology. Cambridge University Press, London, p 612
Wu GX, Liu Y, Zhu X, Li W, Ren R, Duan A, Liang X (2009) Multiscale forcing and the formation of subtropical desert and monsoon. Ann Geophys 27:3631-3644

Yanai M, Li C, Song Z (1992) Seasonal heating of the Tibetan Plateau and its effects on the evolution of the Asian summer monsoon. J Meteor Soc Jpn 70:319-351 